\title{
Construction and Innovation of Ideological and Political Introduction Course
}

\author{
Yuchen $\operatorname{Lin}^{1, *}$ \\ ${ }^{1}$ Beijing Information Technology College, FangYuan West Road, Beijing, China \\ *Corresponding author. Email: linyc@bitc.edu.cn
}

\begin{abstract}
The construction of ideological and political introduction course should be based on the content and objectives of ideological and political course construction, follow the development law of "knowing, thinking and doing", and create "five classes" of ideological and political course, namely "theory class", "proof class", "demonstration class", "experience class" and "task class", in order to implement the fundamental task of Building Morality and cultivating people and guide students to enhance self-confidence, Consciously devote themselves to social work.
\end{abstract}

Keywords: Teaching effect, "five classes" in ideological and political, course construction

\section{INTRODUCTION}

Ideological and political theory course is to carry out ideological and political education and guide students to enhance their patriotism. As teachers of ideological and political course, they should deeply understand the significance of ideological and political course, carry out the construction of ideological and political course, create "five classes" of ideological and political course, and always adhere to that ideological and political course is a "theory course" to give good ideological and political education and make ideological and political course a "proof course" Guide students to enhance their self-confidence, make ideological and political courses into "exhibition Courses" and "experience courses" to cultivate patriotism, and make ideological and political courses into "task Courses" to improve students' practical ability and action ability[1].

\section{WHAT IS THE "FIVE CLASSES" OF IDEOLOGICAL AND POLITICAL COURSE}

The "five classes" of ideological and political course follow the development law of "knowing, willing and doing", solve the practical problems of ideological and political course and improve the teaching effect. It is a curriculum construction innovation integrating various teaching methods, and build the ideological and political course into "theory course", "proof course", "exhibition course", "experience course" and "task course" from the aspects of content, form and process. The innovation of ideological and political course construction should follow the development law of "knowing, willing and doing"[2]. To improve the effectiveness of ideological and political course, we should further clarify the contents and relations of these, "knowledge" is the construction content of Ideological and political course, and study ideological and political education; "Emotion" is to guide students to enhance self-confidence; "Meaning" is to improve students' consciousness; "Line" is to integrate into social work.

The development law of "knowing, willing and doing" is a process of realizing the "unity of knowledge and practice" from cognition, emotional identification, strengthening will and putting it into action. To build the "five classrooms" of ideological and political course is to follow the development law of "knowing, willing and doing" according to the construction content and objectives of ideological and political course, so as to improve the effectiveness of classroom teaching. First of all, we should always adhere to the ideological and political course as a "theoretical course", adhere to the theoretical nature of the ideological and political course, seriously stress the ideological and political education and ideological and political education, and realize the link of recognizing the truth of "knowledge"[3]; Secondly, the ideological and political course should be made into a "proof course", which can prove the scientificity, practicality and effectiveness of the theory through diversified teaching methods, enhance students' "four self-confidence", cultivate patriotic "feeling" and realize the second link of "feeling" identity; Thirdly, the ideological and political course should be made into "exhibition course" and "experience course" to enhance students' consciousness and implement the third link to enhance "meaning" and willpower; Finally, the ideological and political course is made into a "task course" to improve students' practical ability and action ability, practice and harvest new knowledge in the task, and realize the fourth link of "action". Through the "five classes" of ideological and political courses, the circular development of "knowing, willing and doing" has been created. 


\section{SOLVE PRACTICAL PROBLEMS}

Ideological and political teachers need to make great efforts and can solve the problems of "classroom teaching effect still needs to be improved" and "solving the problem of confidence". The two issues of "effect" and "confidence" are interrelated and prerequisite to each other. If the problem of "effect" is solved well, confidence will be improved; Solving the problem of "confidence" will improve the classroom effect. In the middle of the two, ideological and political teachers need to increase teaching research in order to improve their level and self-confidence; Expand ideas to improve teaching effect. Building the "five classes" of ideological and political course is a comprehensive embodiment of teaching research and thinking expansion. How to find the right direction and improve the attractiveness of teaching, we should deeply sort out the practical problems of ideological and political course, clarify its internal logic, accurately focus on key points and improve the attractiveness of teaching design. In terms of course content, students think that the teaching content is abstract and difficult to understand. This problem is directly related to students' problems, because theory comes from practice and guides practice, while students do not understand the modern history of China, and the theory divorced from history is abstract. Only by mastering rich historical knowledge and constructing a correct view of history can they return the abstract theory to its background Root and essence, and students will be more likely to accept new knowledge and understand theory within their familiar framework, so as to improve learning motivation and teaching effect[4].

\section{CREATE 4"FIVE CLASSES"}

"Theory course" is the foundation of classroom teaching and the starting point and foothold of all teaching links. The "proof course" with the theme of exploring the scientificity of "theory course" is to adhere to the unity of politics and academic rationality, constructiveness and criticism, indoctrination and inspiration, convince students with the scientificity of ideological theory, and realize the political nature of ideological and political course; In order to highlight the advantages of "theory course", we should integrate the guidance of values into the teaching of knowledge and improve the students' responsibility and responsibility; Adhere to the unity of explicit education and implicit education in the "experience course", fully tap the educational nature contained in different resources and teaching methods, and realize the effect of moistening things silently; In the implementation of "task class", adhere to the unity of theory and practice, guide students to closely combine their life ideals with the great goal of national rejuvenation, and be a down-to-earth fighter. To create the "five classrooms", we should be student-centered in the whole process of teaching, constantly carry out diversified exploration, adhere to the unity of unity and diversity, the unity of dominance and subjectivity, and realize the teaching objectives in a variety of ways.

\section{1. "Theory classroom"}

"Theory course" is the foundation of the "five classes" of the introduction course, which is the teaching research on the teaching content and educational objectives. The teaching contents are mainly based on teaching materials, timely integrated into the latest achievements of ideological and political education, continuously develop the teaching contents, including self-identity, family and country feelings, moral cultivation, legal awareness and cultural literacy, follow the learning characteristics of higher vocational students, and integrate theoretical learning and experiential learning.

\section{2. "Proof course"}

Ideological and political class should convince people with thorough theories. ideological and political class is not a theoretical memorization class, which should prove the essence of theory with theoretical analysis; ideological and political class is not a policy publicity class, but to understand the practicality and effectiveness of theory [5]; ideological and political class is not a display of historical changes, but to concretize abstract theory with the process of development; guide students in understanding the essence, source and practicality of theory On this basis, we should consciously study ideological and political theories, arm our minds with ideas, and consciously establish the ideals and beliefs of socialist construction.

\section{3. "Exhibition course"}

The ideological and political course should take knowledge as the carrier to guide students to establish values. The "exhibition course" is the medium and intermediate link that adheres to the unity of knowledge and value. The teaching content of the "exhibition course" includes historical processes, historical events and historical stories of the people such as heroes who promote historical development, and integrate value education into these stories.

\section{4. "Experience class"}

"Experience class" The implicit extension of classroom teaching is realized through explicit educational practice activities. The classroom is limited by time and place and the inherent limitations of students' identity. Students lack comprehensive cognition and perception of history and society in the learning process. The important philosophical theoretical basis of experiential teaching is epistemology, and people's cognition starts from perceptual cognition and develops from perceptual cognition to rational cognition 
Knowledge, and then the process from rational knowledge to practice. "Experience course" Through rich online and offline practical activities, students can enhance their real experience in practice. Experiential teaching is no longer limited to book knowledge and classroom, but should put students in an open and diversified learning environment, guide students to actively explore the source of knowledge and the space for development, and pay attention to the use of extracurricular natural and social resources to carry out rich and colorful activities Action is conducive to the overall improvement and harmonious development of students' quality, so that students' mentality is open, free and free from depression; let students open their hands and feet and engage in learning activities independently, so that they can experience the formation of knowledge; respect students' thinking opinions, emotional experience and behavior; when designing open problems and discussion topics, instructional design is based on information development To support, carry out online and offline experience practice activities. Offline experience design includes scenario design, visiting activities, film and television analysis, etc. online experience design includes VR experience, scenario simulation, human-computer interaction, etc.

\section{5. "Task class"}

"Task class" is the end and starting point of the five classes. It realizes the "unity of knowledge and practice" on the basis of theoretical learning, exploring the source and tracing the origin, clarifying the value and establishing self-confidence Practice is the only criterion for testing truth. Use theory to guide practice, enhance theoretical self-confidence, and improve the ability and level of using theory to solve problems; harvest new knowledge, practically enhance and harvest new knowledge in practice, forming a spiral cycle of unity of theory and practice. Relying on "learning by doing, learning by doing" Based on the analysis of learning situation, the discussion teaching method is adopted. Specific activities include case discussion, scenario experience discussion, mind mapping discussion, etc. Let students internalize theoretical knowledge and skills through understanding specific scenarios and practical processes, so as to realize the integration of theory and practice and "learn by doing and do by learning".

The goal of comprehensive practical activity course is to cultivate students' independent and continuous exploration interest through research-based learning, social practice and community service; enable students to obtain rich experience of participating in research, social practice and community service; further improve students' ability to find, ask and analyze problems; and enable students to master basic practical and service skills Cultivate students' spirit of sharing, respect and cooperation; enable students to develop a scientific attitude of seeking truth from facts; cultivate students' sense of service and dedication, sense of social responsibility and sense of mission. Among them, the goal of research-based learning is to guide students to learn to find and raise problems and enhance problem awareness; preliminarily learn the scientific methods of analyzing and solving problems and improve analysis and solution The goal of community service and social practice is to enter the community, understand the society, obtain direct experience and form a correct understanding of the society; participate in community activities, practice social services and adapt to the society Life, improve social practice ability; cultivate social service consciousness, enhance citizens' sense of social responsibility, and form a positive and enterprising attitude towards life[6].

\section{CONCLUSION}

The ideological and political course adheres to the theoretical nature in the teaching content, explains the scientific essence of ideological and political education, enables students to fully theory the scientific law of human social development and establish lofty beliefs; fully feel and experience the historical process and feel the feelings of family and country; actively devote themselves to work and bloom the flowers of youth.

\section{REFERENCES}

[1] On the cultivation of craftsman spirit in the cultivation of applied talents [J]. Han Yingli, Ma Chaoqun. Journal of Hubei second normal university. 2016 (06) https://t.cnki.net/kcms/detail?v=oqvvWN29B9GeBpCz 7T61E7SRoqrXAIcFRXdKRSqtOdCwI210pARd1gev8Paht-Vwl_1dyVNxVrV_hIly4Ic3dgWEt2Jowiq9N6tDWXH60vnuy4SwqdpqWLTyho4NB\&uniplatform=NZKPT

[2] Research on the integration of craftsman spirit into college curriculum in the new era $[\mathrm{J}]$. Lu Yao, Li Huating. Journal of Jilin radio and Television University. 2020 (10) https://t.cnki.net/kcms/detail?v=oqvvWN29B9Gm3ZK MODxogCZIUtL4dHh5-

Ilv1xqpqswmgnS1pK1lwzswlOm3JgBA3Ud0GU2vve Zcydbe5KYGZj3gkmV4c_cJfZN3hhnI_zj9y_5XD81uCkYKQA2pnyU\&uniplatform=NZKPT

[3] Exploration on the combination of craftsman spirit and college students' career development planning $[\mathrm{J}]$. Xue Ying, Hao Wenjuan, Miao Qing. Asia Pacific Education. 2016 (27) https://t.cnki.net/kcms/detail?v=oqvvWN29B9EHE8hta TvajrkFebl3hyvRGAYXOTedHOuzTFuDg_jFo6AJPuB4GdgefXIXRFQ1PpOjdxF6J8P8EbLx75DN5nhFF vbfRKI1RXMi_ZxGeN9ufApYrfwDGT8\&uniplatform $=\mathrm{NZKPT}$ 
[4] Cultivation of craftsman spirit from the perspective of campus culture [J]. Lu Xiaoli. Journal of Suzhou Vocational University. 2020 (04)

https://t.cnki.net/kcms/detail?v=oqvvWN29B9HtyoBDJ

BqgSd4_OCPovWHRKJPdsCGhJ0dtpxZ_r38xwO7Usr MSX15sDTzulp5UogLUOZEqeZ-ho8P7gWU1P-

bC1or6NidzDzMsbMLw1rJ5ITfTiCxGP0ao\&uniplatfo $\mathrm{rm}=\mathrm{NZKPT}$

[5] The influence of Japanese craftsman spirit on the cultivation of Applied Talents in local colleges and universities [J]. Cai lini. Comparative study on cultural innovation. 2020 (18)

https://t.cnki.net/kcms/detail?v=oqvvWN29B9Gep8fvL
6NrxBzavfV7VfxYkFjfjSHS3saCuyg1NPtp1jm0fV2U ZwF3NZFFLvC_5EPDNQFpVhTZFxzsOEYTFeWQA sxPOrYHzYCDMz3V01f8FWwushARh6QW\&uniplatf orm $=\mathrm{NZKPT}$

[6] On the integration of craftsman spirit into college students' Ideological and Political Education [J]. Li Wei. Reform and opening up. 2020 (16) https://t.cnki.net/kcms/detail?v=oqvvWN29B9EE21yX 3S2NLgFYKpuNEhc6NdGBttIj5PhYqa12r4wdrFZvW hDv8bnR-

B5jO199U9Z_xRZAY2D8s0SFMQXEAsXuTGIFEpK uJ4gKBD6H0vtjuEIyYmD1qRgr\&uniplatform=NZKP 